\title{
Jean-Claude Berchet, Chateaubriand
}

\section{Lise Sabourin}

\section{OpenEdition}

\section{Journals}

\section{Édition électronique}

URL : https://journals.openedition.org/studifrancesi/3131

DOI : 10.4000/studifrancesi.3131

ISSN : 2427-5856

\section{Éditeur}

Rosenberg \& Sellier

\section{Édition imprimée}

Date de publication : 1 juillet 2013

Pagination : 467

ISSN : 0039-2944

\section{Référence électronique}

Lise Sabourin, « Jean-Claude Berchet, Chateaubriand», Studi Francesi [En ligne], 170 (LVII | II) | 2013, mis en ligne le 30 novembre 2015, consulté le 02 février 2023. URL : http://journals.openedition.org/ studifrancesi/3131; DOI : https://doi.org/10.4000/studifrancesi.3131

\section{Ce document a été généré automatiquement le 2 février 2023.}

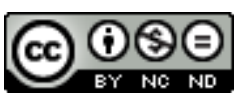

Creative Commons - Attribution - Pas d'Utilisation Commerciale - Pas de Modification 4.0 International - CC BY-NC-ND 4.0

https://creativecommons.org/licenses/by-nc-nd/4.0/ 


\title{
Jean-Claude Berchet, Chateaubriand
}

\author{
Lise Sabourin
}

\section{RÉFÉRENCE}

JEAN-CLAUDE BERCHET, chateaubriand, Gallimard, 2012, «Biographies NRF», pp. 1050.

1 Jean-Claude Berchet, à qui l'on doit la dernière grande édition scientifique des Mémoires d'outre-tombe enrichie de nombreuses notes documentaires, est évidemment le mieux placé actuellement pour écrire cette biographie de Chateaubriand. Aussi le lecteur trouvera-t-il dans son ouvrage, suivis pas à pas, tous les détails de cette longue vie si bien remplie à écrire les réflexions nostalgiques et futuristes à la fois qu'inspirent au premier grand romantique les déceptions de l'action. On prend notamment bien conscience, à lire les méandres de la reconstruction nationale dans les années 1795-1805, puis les difficultés ministérielles du début de la Restauration, enfin les vicissitudes de 1830-32, du poids de l'époque sur cette génération arrivée à l'âge adulte au moment où la France ébranlait la tradition monarchique.

2 Le matériau utilisé par Jean-Claude Berchet est immense, même si la collection où il publie cette biographie, qui vise aussi le grand public, le prive de révéler sa bibliographie, renvoyant aux notes en fin de volume quelques allusions seulement aux ouvrages consultés; l'index nominum heureusement demeure pour retrouver du moins les nombreuses personnes évoquées au passage, toujours bien situées d'une phrase ramassée et efficace. Le lecteur aura donc le plaisir de ressentir le tourbillon de rencontres et de liens que constitue alors la vie du monde aristocratique, même pour le chevalier désargenté qu'est toujours demeuré le «noble pair». Il en ressentait souvent la lourdeur, lui qui ne montrait son caractère «bon enfant» qu'en société choisie, tout en étant capable d'assurer le train de réception fastueux adéquat à un ambassadeur de France à Rome ou à Londres. Mais ce réseau a constitué aussi une aide puissante quand les amis Joubert et Fontanes assurent la notoriété du lancement de ses nouvelles œuvres ou lorsque sa famille sait élaborer le pacte financier nécessaire au calme de leur gestation. 
Soucieux de ne pas se laisser entraîner par la mythification du moi opérée au sein des Mémoires de son grand homme, Berchet adopte un ton mesuré, rectifie certains faits, s'attache à bien restituer le contexte de naissance des œuvres, débrouille tout l'écheveau des amitiés et relations sociales. Le lecteur ne peut s'empêcher parfois de trouver que sa volonté de ne pas apparaître en thuriféraire de l'enchanteur l'amène à amoindrir un peu son personnage. Berchet montre souvent Chateaubriand ballotté par les événements, au point qu'on en oublie la puissance de sa réflexion sur son temps; politiquement, il le voit plus malhabile que maltraité, alors que sa défense de la liberté de la presse et sa conscience aiguë du moment social nous paraissent mériter plus d'éloge. Sans doute Berchet est-il, comme beaucoup de fins connaisseurs d'un grand écrivain, parfois énervé par la récurrence de certaines de ses postulations: on le voit à quelques phrases plus assassines qu'il ne le voudrait probablement («Par une illusion rétrospective, et peut-être de bonne foi, le mémorialiste considère qu'il a joué un rôle essentiel dans la fondation de la revue», à propos du «Conservateur», p. 607). Sur le plan privé, l'on adhère assez facilement à la réhabilitation de Céleste, qui assume finalement avec dévouement une condition d'épouse fort délicate (voir pp. 907-908) et au relativisme réintroduit sur les amours avec Juliette Récamier (Berchet écrit à propos de leur rencontre: «Les choses se passèrent de manière moins romanesque que dans la mise en scène des Mémoires. De longues "préparations" avaient précédé ce coup de foudre», p. 612). Mais sur les œuvres, on se surprend parfois à regretter de les voir présenter comme surtout nées des circonstances: cette vérité n'empêche pas leur qualité dont le caractère exceptionnel n'apparaît guère que par les échos de leur succès.

4 C'est finalement le grand intérêt de cette biographie savante: le lecteur en ressort avec l'envie de relire les Mémoires d'outre-tombe pour les confronter aux faits ainsi attestés et d'autant mieux savourer le charme de l'écriture qui a su les sublimer. N'est-ce pas le but de Chateaubriand: transformer la réalité par la littérature et insuffler l'espoir de la transcender? 